\title{
MÍDIA E MEIO AMBIENTE: A REPRESENTAÇÃO DE ATORES SOCIAIS EM NOTÍCIAS SOBRE AS TRAGÉDIAS DE MARIANA E BRUMADINHO
}

\author{
Matheus Batista da Silva ${ }^{1}$, Carolina Lopes Araújo² e Janaína Siqueira Silva ${ }^{3}$ \\ 1,2 e 3 Universidade de Brasília, Brasil. ${ }^{1}$ mathewsb.silva@gmail.com² carolinaaraujo@unb.br \\ ${ }^{3}$ siqueira.janaina6@gmail.com
}

\begin{abstract}
Resumo. Em menos de quatro anos da tragédia de Mariana (2015), a Vale protagonizou mais um episódio, em Brumadinho (2019), consolidado como o maior desastre ambiental em termos de perda de vidas humanas. Para dar voz aos afetados pelas tragédias, a mídia assume papel central com seu poder de influenciar a opinião pública. Baseado no relatório Media Ownership Monitor Brasil (2017), o presente trabalho buscou analisar notícias publicadas em portais jornalísticos online brasileiros G1 e Folha de São Paulo, e nos portais internacionais BBC e The New York Times sobre as tragédias. Recorreu-se à análise de discurso crítica (ADC), utilizando-se o software webQDA no tratamento e codificação de dados, para analisar quais os atores mais acionados para falar sobre as tragédias de Mariana e Brumadinho e como a voz autoral representa os principais atores sociais e institucionais nas notícias. Os veículos reconhecem a responsabilidade do poder público e das empresas. Mas a exclusão das vozes militantes e o não reconhecimento da comunidade local como vítima das tragédias, faz-se questionar se a mídia tem usado sua influência para a mudança de estruturas sociais. Leniência e irresponsabilidade dos atores, especialmente, pelos governos e grandes empresas, têm gerado graves custos ambientais, políticos e sociais para o Brasil.
\end{abstract}

Palavras-chave: Análise de Discurso Crítica; webQDA; Mídia e Meio Ambiente; Brumadinho; Mariana.

\section{MEDIA AND ENVIRONMENT: THE REPRESENTATION OF SOCIAL ACTORS IN DIGITAL PRESS ABOUT THE TRAGEDIES OF MARIANA AND BRUMADINHO}

\begin{abstract}
Almost four years later the tragedy in Mariana (Minas Gerais, Brazil) at 2015, the mining company Vale was, once again, the protagonist at a tragic episode occurred in Brumadinho (Minas Gerais, Brazil), at 2019. Such event has been reported as the major environmental disaster in terms of loss of human life. The press has a central role in giving voice to those affected by the tragedies due its power to influence public opinion. Bearing this in mind, the present paper aims to reveal which actors have space on the news to talk about the tragedies of Mariana and Brumadinho and how the authorial voice represents its' main social and institutional actors. In order to frame the analysis corpus, news articles published at the date, one week later and one year later each of those tragic events were collected from the most important journalism websites in Brazil, chosen on basis the Media Ownership Monitor Brasil report (2017). The press website considered were, in national scope, the websites of Portal G1 and Folha de São Paulo, and in the international scale, BBC and The New York Times websites. The data analysis process applied the sociodiscoursive categories from Critical discourse analysis assisted, in the treatment and coding data, by webQDA. The analysis has showed that the media recognizes the government and companies as responsible for the tragedies. But it questionable if the media's influence can be used to change social structures that could have crucial importance in a context in which the leniency and irresponsibility of the actors, especially governments and large companies, have been generating serious environmental, political and social costs for Brazil.
\end{abstract}

Keywords: Critical Discourse Analyses; webQDA; Media and Environment; Brumadinho; Mariana. 


\section{INTRODUÇÃO}

O Brasil possui um histórico significativo de tragédias envolvendo grandes empresas e a destruição do meio ambiente. Os atores institucionais brasileiros parecem não ter aprendido com a tragédia de Mariana, em 2015, envolvendo a empresa Samarco, controlada pela jointventura formada entre a Vale e a BHP Billiton. Em menos de quatro anos do rompimento da barragem de Fundão, a Vale e empresas associadas protagonizaram mais um episódio, em Brumadinho (2019), que se consolidou como o maior desastre ambiental em termos de perda de vidas humanas. Novamente o país se viu diante de uma comoção que ultrapassou as fronteiras nacionais e questionou a efetividade do poder público na proteção da vida humana e do meio ambiente. Para dar voz aos atores sociais afetados pelas duas tragédias, a mídia assume papel central com seu poder de influenciar a opinião pública. Portais de notícias do Brasil e de diversos países retrataram os casos, contribuindo, assim, com a cobrança social por respostas e adoção de medidas para se fazer justiça às milhares de vítimas fatais e sobreviventes. O presente trabalho pretende analisar, pela perspectiva da metodologia qualitativa, notícias publicadas em portais jornalísticos online brasileiros G1 (Globo), UOL (Folha de São Paulo), e nos portais internacionais BBC (British Broadcasting Corporation) e The New York Times sobre as duas tragédias. Recorreu-se à análise de discurso crítica, utilizando-se o software webQDA no processo de tratamento e codificação de dados, para analisar quais são os atores mais acionados para falar sobre as tragédias de Mariana e Brumadinho e identificar como a voz autoral os representa.

\section{METODOLOGIA}

Os passos do percurso metodológico, adaptado com base nas etapas de planejamento de pesquisa proposta por Ramalho e Resende (2011) estão sintetizados no Quadro 1:

Quadro 1. Passos da análise da representação de atores e discursos presentes em notícias de portais de mídia online

\begin{tabular}{|c|c|c|}
\hline passo & $\begin{array}{l}\text { Formulação das questões } \\
\text { de pesquisa }\end{array}$ & $\begin{array}{l}\text { Identificar e analisar "quais são as vozes e discursos predominantes nas } \\
\text { notícias midiáticas nacionais e estrangeiras sobre os casos de Mariana e } \\
\text { Brumadinho" }\end{array}$ \\
\hline $\begin{array}{l}2^{\circ} \\
\text { passo }\end{array}$ & $\begin{array}{l}\text { Definição de critérios para } \\
\text { coleta dos dados }\end{array}$ & $\begin{array}{l}\text { Explorar e selecionar portais de notícias nacionais e internacionais mais } \\
\text { visitados no Brasil que noticiaram as tragédias de Mariana e Brumadinho }\end{array}$ \\
\hline $\begin{array}{l}3^{\circ} \\
\text { passo }\end{array}$ & $\begin{array}{l}\text { Leitura dos dados de } \\
\text { análise }\end{array}$ & $\begin{array}{l}\text { Identificar quais lentes da Análise de Discurso Crítica podem ser aplicadas no } \\
\text { corpus }\end{array}$ \\
\hline & $\begin{array}{l}\text { Análise qualitativa do } \\
\text { corpus de análise }\end{array}$ & $\begin{array}{l}\text { Gerar categorias de codificação das notícias e classificá-las com a ajuda do } \\
\text { software webQDA de análise qualitativa }\end{array}$ \\
\hline passo & $\begin{array}{l}\text { Análise interpretativa da } \\
\text { representação de atores } \\
\text { sociais e intertextualidade }\end{array}$ & $\begin{array}{l}\text { Analisar os dados pelas lentes da Análise de Discurso Crítica (ADC), } \\
\text { especificamente pelas categorias de interdiscursividade e representação de } \\
\text { atores sociais. }\end{array}$ \\
\hline
\end{tabular}

Fonte: Elaboração dos autores. 
Com base na perspectiva da ADC, que busca entender a relação linguagem-sociedade, foi definido o paradigma interpretativo crítico que permitiu problematizar a influência da mídia na formação de opinião pública acerca de tragédias de caráter político-socioambiental, que envolve, diretamente, o uso da linguagem. O percurso metodológico proposto para este trabalho buscou aportar métodos que contribuíssem para desvelar a produção discursiva midiática e a representação (e protagonismo) de atores diversos perante situações de conflitos socioambientais. Para isto foram formuladas questões de pesquisa capazes de nortear as possibilidades metodológicas em termos analíticos, focalizando na interpretação dos aspectos discursivos:

1. Quais são os atores mais acionados, com legitimidade para contar os fatos ocorridos em Mariana e Brumadinho?

2. Como a voz autoral representa os principais atores sociais e institucionais presentes nos textos?

Nas próximas seções são detalhadas as estratégias usadas para gerar e analisar os dados, a fim de responder aos objetivos pretendidos e às questões de pesquisa.

\subsection{Coleta de Dados}

A pesquisa demandou uma abordagem predominantemente documental, tendo como material empírico documentos de mídia online, elaborados por portais de notícias nacionais e internacionais.

A escolha dos dados baseou-se no relatório de Monitoramento da Propriedade da Mídia (Media Ownership Monitor), criado pela ONG internacional de Direitos Humanos Repórteres Sem Fronteiras (RSF), que resultou na criação de um banco de dados sobre os maiores veículos e grupos de mídia, além de seus interesses políticos e econômicos. No Brasil, a pesquisa foi feita pela ONG Intervozes - Coletivo Brasil de Comunicação Social e indicou grande concentração no meio digital pelos portais de notícias Globo.com e UOL, do Grupo Globo e do Grupo Folha, conforme ilustra a Figura 1: 


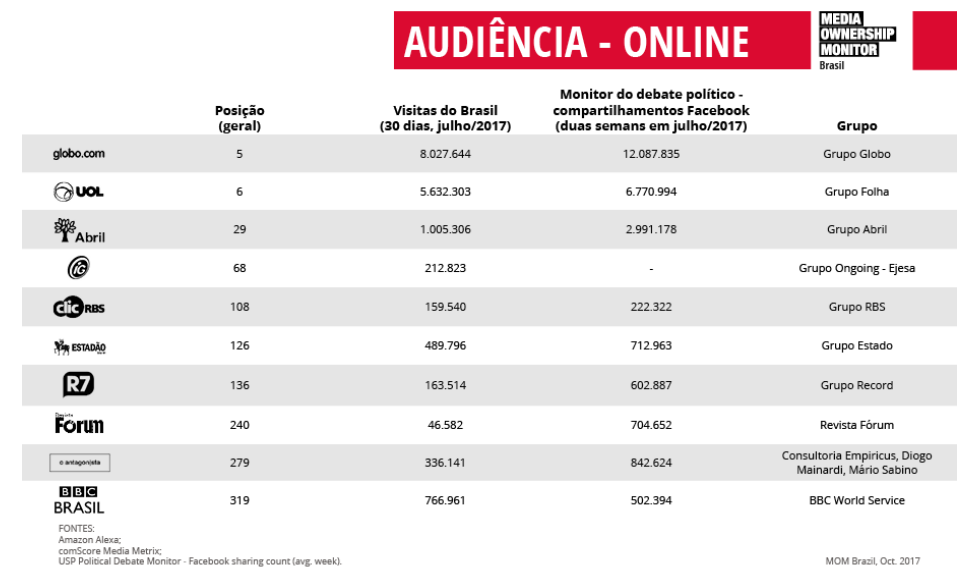

Figura 1. Ranking de audiência de mídia online no Brasil Fonte: Relatório do Media Ownership Monitor Brasil - MOM (2017).

Para definir a lista dos principais veículos na categoria "mídia digital", os veículos foram selecionados com base na audiência e em "seu potencial de influenciar a opinião pública" (Reporters Without Borders \& Intervozes, 2017, p. 16). Segundo o relatório, ainda, há um único portal estrangeiro - BBC - na lista dos mais acessados no Brasil. Como este trabalho objetiva analisar notícias midiáticas de portais nacionais e estrangeiros, julgou-se necessário incluir mais um portal estrangeiro com notícias relacionadas às tragédias. A pesquisa retornou uma reportagem especial do portal The New York Times sobre o caso de Brumadinho (2019), que resgata a memória sobre o caso de Mariana (2015).

A comunicação midiática tem, entre outros, o objetivo de difundir temas significativos para a sociedade, podendo influenciar a opinião pública. Sobre o poder da mídia, Mendonça (2020), discute o trabalho de Vieira e Resende (2016), e aponta que a mídia dissemina modos de mundo aptos a contribuir para a manutenção de estruturas sociais. A mídia exerce, também, um poder mediador ao "selecionar fontes de informação e assuntos para as histórias, ao seguir rotinas jornalísticas consagradas, ao decidir atores representados na arena pública, o que será dito a respeito deles e, em especial como será dito" (van Dijk, 2015 , p. 73). Ressalta-se que, apesar desse papel mediador, os leitores ou ouvintes avaliam, interpretam e representam notícias jornalísticas de maneiras distintas, conforme os contextos socioeconômicos, políticos e socioculturais ao qual estão inseridos.

Considerando o alcance das notícias publicadas em mídias online, entendeu-se que a análise de discurso crítica seria fundamental para comparar a representação discursiva desses dois momentos trágicos da história político-socioambiental brasileira. Optou-se por analisar apenas notícias em português, mesmo dos portais estrangeiros, para favorecer a 
análise de categorias semânticas presentes no corpus de pesquisa. Foi definido um recorte temporal de um ano, sendo escolhidas notícias do dia das tragédias, de uma semana depois e, por fim, de um ano dos acontecimentos. Apenas o portal The New York Times não seguiu esta definição. Pautada nesses critérios, a busca retornou um total de 19 textos que compuseram o corpus de análise do trabalho. Para tratamento dos dados, fez-se proveitoso o auxílio do software webQDA (Sousa, Costa \& Moreira, 2019).

\subsection{Codificação e Análise Qualitativa com o software webQDA}

Os textos das matérias selecionadas foram importados para o software. O programa foi útil para filtrar informações relevantes em macro análise, que, em um segundo momento, estiveram no foco da interpretação e análise discursiva. Na plataforma do WebQDA foi criado um projeto para trabalhar os dados, no qual foram criadas pastas separando as notícias de Mariana e Brumadinho. Com a ferramenta "Descritores", as fontes foram codificadas em Mídias Nacionais e Internacionais, separando também os jornais objetos de análise conforme o Mapa de Códigos a seguir:

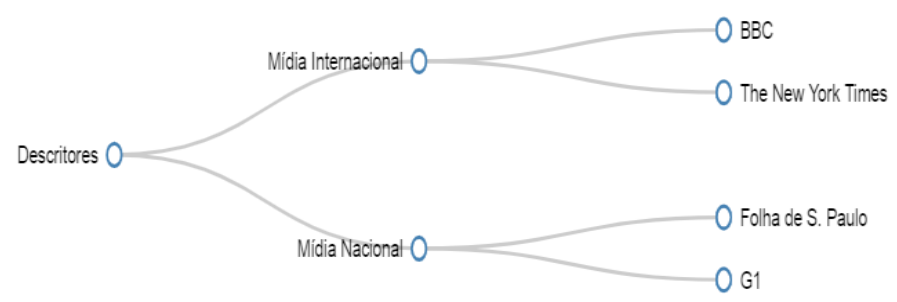

Figura 2 Mapa de Códigos Descritores realizados na aba Questionamentos do webQDA Fonte: Elaborado pelos autores com o software webQDA.

Essa divisão facilitou a identificação das mídias e, posteriormente, permitiu analisar os resultados da pesquisa com base em cada mídia, podendo filtrar os resultados para comparação e discussões relevantes para o trabalho. $O$ trabalho analítico consistiu numa primeira leitura dos textos no software webQDA, identificando todos os atores sociais e institucionais mencionados nas notícias. Após a marcação, foram mapeados, com a ferramenta Códigos Árvore, os tipos de atores que foram nomeados nas seguintes categorias: I. Ativistas/Militantes, II. Atores Internacionais, III. Comunidade Local, IV. Empresas, V. Especialistas, VI. Governo e VII. Organizações Não Governamentais (ONGs). A representação destes atores no texto também foi codificada segundo duas categorias: a. Fala do ator e b. Fala sobre o ator, com o objetivo de responder as perguntas iniciais da pesquisa. 


\subsection{Análise de Discurso Crítica (ADC) como teoria e método de investigação}

A Análise de Discurso Crítica (ADC) fornece elementos para a realização de pesquisas qualitativas de discurso sendo seu principal material empírico o texto (Ramalho \& Resende, 2011). Para Fairclough (2012), a ADC é, ao mesmo tempo, uma teoria e um método analítico com atenção especial para os processos de representação discursiva e para as relações de força entre atores sociais.

Acosta e Resende (2018) afirmam que a linguagem pode provocar mudanças sociais, logo, está interligada com outras instâncias da vida social como os valores, ideologias e as relações sociais. Uma das características fundamentais desse campo teórico-metodológico é a interdisciplinaridade, pois reconhece que, para analisar discursivamente problemas sociais é preciso estabelecer conexões com diferentes áreas do conhecimento (Resende, 2012). Outra característica relevante da ADC é que as pesquisas assumem posição explícita diante de problemas sociais de cunho discursivos (Resende, 2017). Seu caráter posicionado rompe com a imparcialidade científica, pois é "um tipo de investigação analítica do discurso que estuda principalmente as formas como o abuso do poder social, a dominação e a desigualdade são conquistados, reproduzidos e contestados, por meio de textos, no contexto social e político" (van Dijk, 2001, p. 352).

A ADC fornece categorias analíticas que auxiliam na investigação de efeitos de textos em práticas sociais e vice-versa, permitindo identificar nos textos formas particulares de significar e representar o mundo (Ramalho \& Resende, 2011). Mas é necessário, antes, ter acesso aos textos para, então, identificar as categorias mais eficazes para a análise (Acosta \& Resende, 2018), considerando-se as questões de pesquisa e características dos textos. Com a leitura do corpus de análise observou-se o acionamento de muitas vozes a dizer sobre as tragédias de Mariana e Brumadinho. Diante disso, a categoria de Intertextualidade mostrou-se relevante para descobrir quais atores sociais têm maior espaço de fala (Ramalho \& Resende, 2011; Mendonça, 2020). Mostrou-se, também, importante identificar como esses mesmos atores sociais são representados nas notícias, usando, para tanto, as categorias de representação de atores sociais propostas por Van Leeuwen (2008).

\section{ANÁLISE DE DADOS E DISCUSSÕES}

No webQDA realizou-se uma pesquisa com a ferramenta "Palavras mais frequentes", presente no menu "Questionamentos", para verificar os campos semânticos ativados pelas 
escolhas lexicais nos textos. Foram geradas nuvens de palavras, para os textos da mídia nacional e internacional, com as 100 palavras mais frequentes, tendo como argumento o mínimo de 6 caracteres.

A nuvem de palavras apresentada na Figura 3 contém os 95 vocábulos mais utilizados nos 12 textos de mídia nacional sobre as tragédias de Mariana e Brumadinho. Os termos "barragem" (77 ocorrências); "rompimento" (57); "segundo" (45) e "Feijão" (12), foram suprimidos a fim de priorizar a análise comparativa da ocorrência de outros termos relevantes nos documentos. Inserem-se na Fig. 3, portanto, somente os termos que se repetem entre 75 vezes ("lama") e 12 vezes ("mina").

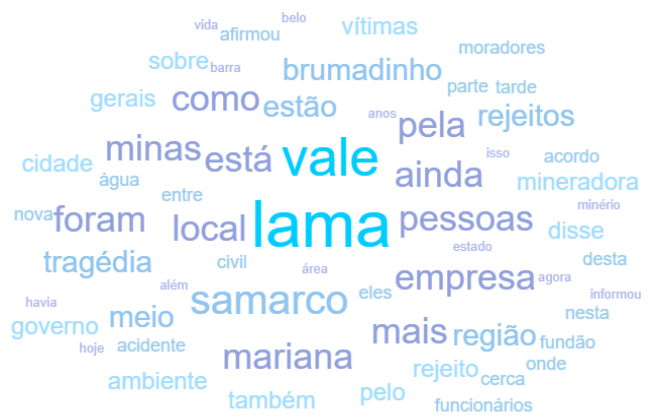

Figura 3 Palavras frequentes no corpus de análise de mídias nacionais (G1 e Folha de S. Paulo) Fonte: Elaborado pelos autores com o software webQDA.

As colocações são padrões mais ou menos regulares de co-ocorrência entre palavras, podese chegar a esses padrões observando quais palavras precedem e seguem com maior frequência a palavra que esteja em foco (Fairclough, 2003). Pela análise lexical, observa-se que o termo "lama", referente ao rompimento da barragem em Mariana, surge 75 vezes nos textos assumindo relevância para condução de debates relacionados à tragédia. $O$ ator central do acontecimento é a lama que cobriu as empresas, casas e a comunidade local. Em diversos trechos das notícias é possível observar que o vocábulo está associado ao desaparecimento de familiares da comunidade local.

Há uma diferença relevante nas menções sobre as empresas vinculadas às duas tragédias ambientais. O vocábulo "Vale" apresenta destaque nas notícias, com 62 citações, enquanto "Samarco" apresenta apenas 44 menções. Essa diferença pode ser explicada pela responsabilização da empresa Vale, que é uma das donas da mineradora Samarco. Podese observar também a ausência de "Governo" entre as palavras mais frequentes dos textos,

\footnotetext{
${ }^{1}$ Vocábulo referente à região do Córrego do Feijão
} 
com uma pequena soma de 23 menções, denotando baixa influência do campo semântico relacionado ao Estado, diminuindo assim a corresponsabilidade de órgãos nacionais, estaduais e municipais nas tragédias ocorridas em Minas Gerais.

A nuvem de palavras apresentada na Figura 4 contém os 88 vocábulos mais utilizados nos 7 textos de mídia internacional sobre as tragédias de Mariana e Brumadinho. Assim como no caso anterior, foram suprimidas da nuvem os vocábulos que não ofereceram elementos relevantes para análise, como artigos e preposições. Inserem-se na Figura 4, portanto, somente os termos que se repetem no texto entre 62 vezes ("Vale") e 8 vezes ("sirenes").

Figura 4 Palavras frequentes no corpus de análise de mídias internacionais (BBC e The New York Times) Fonte: Elaborado pelos autores com o software webQDA.

A análise lexical mostra que o vocábulo "Vale" ganha destaque também nas notícias dos portais internacionais, sendo mencionado 62 vezes. Em contrapartida, o vocábulo "Samarco" tem ainda menos destaque nas notícias internacionais, somando 15 menções. Vale ressaltar que, nesse caso, a nuvem de palavras apresenta o vocábulo "disse" como o quarto mais mencionado (39 ocorrências), chamando a atenção para a análise de intertextualidade que será apresentada a seguir. A análise aponta, assim, que os portais de notícias internacionais pesquisados assumem seu poder mediador, selecionando atores como fontes de informação.

\subsection{Análise de intertextualidade}

Acosta e Resende (2018) defendem que existem diversos modos de construir a intertextualidade e que "ao dar maior ou menor espaço a uma voz, mais ou menos explicitamente, o/a autor/a do texto demonstra qual o seu alinhamento e qual a importância que atribui às vozes que atualiza em seu ato linguístico" (Acosta \& Resende, 2018, p. 438). Para Ramalho e Resende (2011) a intertextualidade tem como foco analisar quais são as vozes articuladas ou ausência de vozes nos textos, além das maneiras como são articuladas. Neste trabalho, a análise de intertextualidade busca descobrir quais vozes 
assumem protagonismo nas notícias, com legitimidade para contar os fatos ocorridos em Mariana e Brumadinho. Para esse fim, a ferramenta "Matriz" do WebQDA se mostrou útil. Com as falas dos diversos atores mapeadas e dividas em categorias, de acordo com a esfera a qual estes atores pertencem, a Matriz, gerada a partir da ferramenta "Questionamento" foi utilizada para cruzar os códigos de classificação referente aos atores sociais (fala do ator) e descritores (portal de notícia). Os dados gerados foram copiados para uma tabela do MSOffice Excel para geração do gráfico apresentado na Figura 5 que auxilia nas discussões que se seguem.

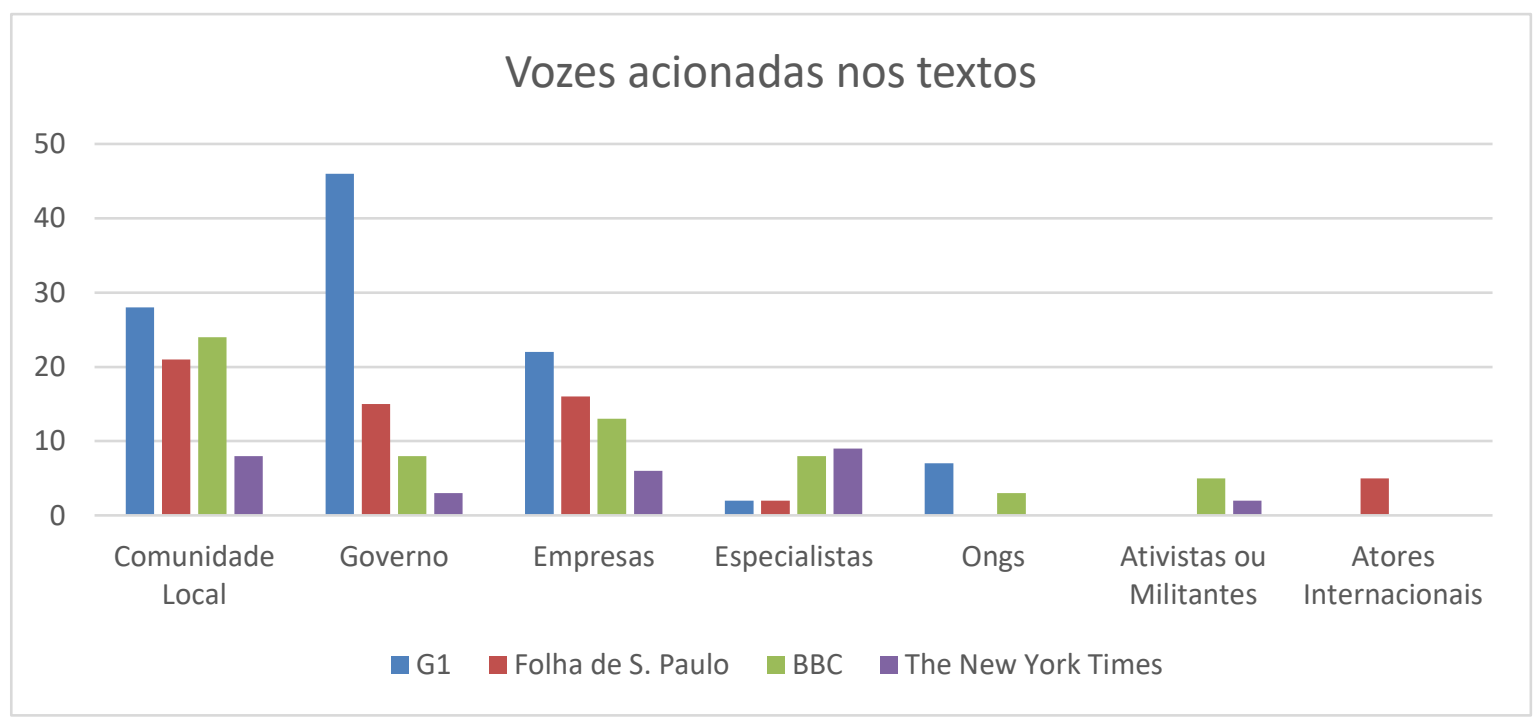

Figura 5 Cobertura quantitativa das vozes acionadas nos textos para análise de intertextualidade Fonte: Elaboração dos autores.

A comunidade local foi a fonte mais acionada nas notícias com 81 codificações. Em seguida, aparece o governo (72), empresas (57), especialistas (21), ONGs (10), ativistas (7) e atores internacionais (5). Como a principal afetada pelas tragédias, pela proximidade com os locais dos rompimentos das barragens e por serem vítimas e/ou familiares de pessoas que morreram, a comunidade se auto representa contando a versão dos fatos. Chama atenção o surgimento da voz do governo como a segunda mais procurada pela imprensa. Por ser responsável pelas ações e políticas públicas, o governo é acionado nesses casos para explicar os motivos de grandes empresas estarem envolvidas em tragédias mesmo passando por fiscalização. Destaca-se, também, que as esferas do governo mais acionadas pela mídia foram os Ministérios e as forças policiais. 
Na mídia brasileira, representada pelos portais G1 e Folha de São Paulo, ganham maior espaço de fala os representantes do Governo (61 codificações), o que pode indicar posicionamento dos textos no exercício de influência acerca dos fatos contados sobre as tragédias (Fairclough, 2001; Ramalho e Resende, 2011). Dessa forma, as mídias reproduzem "maneiras de representar o mundo atreladas a determinados grupos hegemônicos, em razão da pressão discursiva que esses grupos exercem sobre o conjunto da sociedade (Acosta \& Resende, 2018, p. 435). Apesar do destaque das falas do governo, no entanto, observa-se baixo acionamento da voz do Governo Federal nas notícias sobre as duas tragédias, 5 referências a falas nos anos de 2015 e 2019. Vale ressaltar que nesse período o Brasil teve dois mandatos presidenciais, de Dilma Roussef e Jair Bolsonaro. Há, no corpus, apenas uma menção à ex-presidente Dilma de caráter assistencial (Folha de São Paulo, 2015), demonstrando uma colaboração passiva e distante. As respostas dos governos às demandas socioambientais demonstram desinteresse pela busca de responsáveis, aos quais, inclusive, por parte do governo vigente em 2019, Jair Bolsonaro, coube apenas a responsabilidade de lidar com os problemas: "Ele evitou listar culpados, mas disse que caberia à Vale se antecipar a problemas" (Folha de São Paulo, 2019). A fala do presidente, também, ao retratar os afetados como "eventuais vítimas", omite as causas e responsabilidades, além de naturalizar os impactos causados à população. O uso do vocábulo "eventuais" na fala do presidente se presta como modalizador epistêmico, mitigando representação dos afetados como verdadeiras vítimas das tragédias. Nos portais brasileiros percebe-se, também, baixo acionamento de especialistas (4 codificações) e ausência da voz de ativistas/militantes que são atores importantes em conflitos socioambientais. A exclusão desses atores cumpre função ideológica, contribui para a manutenção da impunidade de atores institucionais e causa a exclusão da voz do meio ambiente como vítima das tragédias.

Já na mídia internacional, representada pelos portais da BBC e o The New York Times, segue-se o destaque para a versão dos fatos contada pela comunidade afetada pelas tragédias (32 codificações), seguido pelas empresas (19) e especialistas (17). Os portais se posicionam explicitamente diante das duas tragédias, trazendo questionamentos às empresas e dando espaço para um ator social que a mídia brasileira desconsiderou, os ativistas/militantes (7 codificações). Mesmo sendo pouco acionado, esse ator social teve destaque aproximado ao do Governo (11). Essa articulação explícita, como aponta Ramalho e Resende (2011, p. 33), "tende a ser disciplinadora ou transformadora em relação a lutas 
de poder" e contribui para o confrontamento dos poderes públicos e empresarial, uma vez que grupos militantes tendem a se posicionar diante de tragédias socioambientais.

Nos veículos brasileiros, há apenas 7 codificações referentes à voz de atores internacionais, representado pela Organização das Nações Unidas. Nos veículos internacionais não foram identificados acionamentos desses atores.

\subsection{Representação de atores sociais e institucionais}

Conforme van Leeuwen (2008) as representações de práticas sociais são construídas por pessoas particulares a partir de um determinado ponto de vista e, por isso, os atores envolvidos nas práticas sociais são representados de diferentes maneiras. Araújo, Carmo e Fraga (2018) explicam dois modos principais para analisar a representação de atores sociais, baseados na teoria de van Leeuwen (2008): através dos Modos de Representação, estratégia que pode ser utilizada para descobrir, por exemplo, se os atores sociais são representados individualmente ou coletivamente; e os Modos de Referência, lente pela qual pode-se observar as palavras e conotações utilizadas no texto ao mencionar os atores sociais. Esta seção apresenta os resultados analíticos da representação dos principais atores sociais envolvidos nas tragédias de Mariana (2015) e Brumadinho (2019).

Para identificar os modos de representação nos textos foram mapeadas, no webQDA, todas as referências aos atores sociais, e separadas em categorias que correspondem a 'fala+sobre+ator' (fala sobre o governo, fala sobre as empresas etc), sendo subdivididas de acordo com a esfera que cada ator mencionado pertence, por exemplo, na categoria do Governo subdividiu-se em Governo Federal, Estadual, Ministérios, Órgão Ambientais, Prefeituras, Forças Policiais e Defensoria Pública. Os textos fazem menção ao governo 150 vezes. Em 30 trechos o governo é representado coletivamente (menções com mais de um órgão), 21 referências são feitas com base na funcionalização e identificação de atores do governo e, apenas 5 vezes, há generalização do governo com termos como o 'poder público no Brasil' (Folha de São Paulo, 2020). As empresas são representadas individualmente e por nomeação, com categorização coletiva menos expressiva (5 ocorrências), que ocorre quando são atribuídas as responsabilidades coletivas pelas tragédias. A Vale é a instituição mais mencionada nos textos (79 codificações), seguida da Samarco (40), BHP Billiton (11) e Tüv Süd (5), responsável pela certificação da estabilidade das barragens que se romperam. 
Acerca da comunidade local foram observadas variações significativas nos modos de representação. Os termos utilizados para representar as comunidades envolvidas nas tragédias, conforme a quantidade de codificações, foram: família/parentes das vítimas (13), moradores (11), pessoas (7), comunidade (5), mortos/corpos (5), sobreviventes (3), população (2) e afetados (1). Nota-se nos termos de definição da comunidade local um distanciamento do conceito de vítima. Ao fazer referência à comunidade, que também foi vítima das tragédias, as notícias colocam o ator social em segundo plano e demonstra considerar como vítima apenas vítimas fatais. Apenas a Folha de São Paulo (2015) faz referência aos afetados como 'comunidades vítimas'. Há, ainda, uma separação clara nos textos de tratamento entre sobreviventes e vítimas fatais. Ao representar vítimas fatais é utilizado o termo 'corpos' que enfatiza impessoalização, enquanto ao mencionar os sobreviventes retirados com vida o termo 'pessoa' é utilizado.

Acerca dos qualificadores dos atores sociais, ao se referir às empresas e ao governo, a mídia assume posição explícita e atribui responsabilidades a esses atores. Os principais termos usados para qualificar o governo demonstram um caráter avaliativo da (in)capacidade de atuação para proteção da população. O governo é referido como 'despreparado'; que não se mostra 'competente'; e precedido pelo termo 'inépcia', termos que são, também, associados às empresas Vale, Samarco, BHP Billiton e Tüv Süd. Sobres a responsabilidade das empresas pelas acusações de crimes ambientais e homicídios, o texto enfatiza que "não é trivial provar o dolo de executivos e engenheiros" (Folha de São Paulo, 2020) por protagonizarem o "maior desastre em termos de vidas humanas dos últimos 30 anos no mundo" (Passarinho, 2019).

\section{CONSIDERAÇÕES FINAIS}

Pela análise discursiva crítica é possível afirmar que há uma diversidade de atores sociais representados nas notícias. Ao representar os atores sociais e institucionais, os veículos reconhecem a responsabilidade do poder público e das empresas. A comunidade local é representada como a principal afetada pelas duas tragédias e, portanto, foi a voz mais acionada como fonte das matérias para contar sua versão dos fatos. Assim, as mídias assumem seu poder político de formação da opinião pública, mas pecam por distanciar a comunidade local dos impactos sociais, econômicos e ambientais, uma vez que não a reconhece como vítima das tragédias. O meio ambiente também não é representado diretamente como vítima das tragédias, apesar de serem estas representadas como 
desastres ambientais. A exclusão das vozes militantes/ativistas em defesa dos interesses da população local e do meio ambiente pode mitigar as pressões sociais para a formulação de políticas eficazes para prevenção de novas tragédias.

Toda essa oscilação de uso de poder, representada discursivamente nos textos da imprensa digital, aporta a exigência de se questionar se a mídia tem usado sua influência para a mudança de estruturas sociais as quais têm gerado graves custos ambientais, políticos e sociais para o Brasil.

\section{REFERÊNCIAS}

Acosta, M, \& Resende, V. (2018) Apropriação da análise de discurso crítica em uma discussão sobre comunicação social. Revista de Estudos da Linguagem, pp. 421-454.

Araujo, C., Carmo, E., Fraga, R. (2018). Percurso de Jovens Pesquisadores em Investigação Qualitativa Interdisciplinar embasada na Análise de Discurso Crítica (ADC) com o auxílio do Software NVivo. Fortaleza: Atlas CIAIQ 2018. Acesso em 19 de mar de 2020, disponível em https://proceedings.ciaiq.org/index.php/ciaiq2018/article/view/1725/1678

Fairclough, N. (2001). Discurso e Mudança Social. (I. Magalhães, Trad.) Brasília: Editora UnB.

Fairclough, N. (2003) Analysing discourse: textual analysis for social research. London: Routledge.

Fairclough, N. (2012). Análise Crítica do Discurso como método de pesquisa social científica. Linhas D'Água, 25(2), pp. 307-329.

FOLHA DE SÃO PAULO. Rompimento de barragens atinge dois distritos em Mariana (MG). Folha de São Paulo, São Paulo, 11 nov. 2015. Disponível em: <https://m.folha.uol.com.br/cotidiano/2015/11/1702906rompimento-de-barragens-atinge-distritos-em-mariana-mg.shtml?origin=folha>. Acesso em: 15 mar. 2020.

FOLHA DE SÃO PAULO. Barragem se rompe e casas são atingidas em Brumadinho, Grande BH. Folha de São Paulo, São Paulo, 25 jan. 2019. Disponível em:

<https://www1.folha.uol.com.br/cotidiano/2019/01/barragem-se-rompe-e-casas-sao-atingidas-embrumadinho-grande-bh.shtml>. Acesso em: 15 mar. 2020.

FOLHA DE SÃO PAULO. Brumadinho, 1 ano. Folha de São Paulo, São Paulo, 22 jan. 2020. Disponível em <https://www1.folha.uol.com.br/opiniao/2020/01/brumadinho-1-ano.shtml>. Acesso em: 15 mar. 2020.

Mendonça, D. (2020) População em situação de rua e políticas públicas: representações na Folha de São Paulo. [Dissertação de Mestrado]. PPGL/UnB. Disponível em: https://repositorio.unb.br/handle/10482/36334. Acesso em 23 fev 2020.

Passarinho, Nathalia (2019). Tragédia em Brumadinho: As 5 lições ignoradas após tragédia de Mariana. BBC NEWS, Londres, 01 fev. 2019. Disponível em: <https://www.bbc.com/portuguese/brasil-47077083>. Acesso em: 15 mar. 2020.

Ramalho, V., \& Resende, V. (2011). Análise de discurso (para a) crítica: o texto como material de pesquisa. Campinas: Pontes Editores.

Reporters Without Borders (RSF) \& Intervozes. (2017) Ownership Monitor Media Brasil: Quem controla a mídia no Brasil?. Disponível em: <brazil.mom-rsf.org/en/>. Acesso em: 21 mar. 2020. 
Resende, V. (2012) Análise de Discurso Crítica como Interdisciplinar para a Crítica Social: Uma Introdução. In: I.F. MELO (org), Introdução aos estudos críticos do discurso: teoria e prática, pp. p. 99-112. Campinas: Pontes.

Resende, V. (2017) Abordagem teórico-metodológica para análise interdiscursiva de políticas públicas. Atlas CIAIQ 2017. Acesso em 21 de mar de 2020, disponível em https://proceedings.ciaiq.org/index.php/ciaiq2017/issue/view/21

Sousa, F. N., Costa, A., \& Moreira, A. (2019). webQDA [software]. Aveiro: Microio/Ludomedia.

Souza, F., Costa, A., Moreira, A., Souza, D., \& Freitas, F. (2016). webQDA: manual de utilização rápida. Aveiro: UA Editora. Acesso em 21 de jan de 2019, disponível em http://hdl.handle.net/10773/16171

Van Dijk, T. (2001) Critical Discourse Analysis. In: Tannen, D., Schiffrin, D.; Hamilton, H. (orgs.). Handbook of Discourse Analysis, pp. 352-371. Oxford, Blackwell.

Van Dijk, T. (2015) Discurso e poder. São Paulo: Contexto.

Van Leeuwen, T. (2008). The representing of social actors. Em T. Van Leeuwen, Discourse and practice: New tools for critical discourse analysis, pp. 23-54. New York: Oxford university Press.

Vieira, V., Resende, V. (2016) Análise de discurso (para a) crítica: o texto como material de pesquisa. 2. ed. Campinas: Pontes. 